Secondly. We desire to be permitted to retire from the service on full-pay after twenty or twenty-one years' fall-pay service.

Thirdly. It is essentially necessary that all punishments, including the branding the letters "B. C.," should be inflicted in some other place than the hospital, by some person entirely unconnected with the hospital, and under the superintendence of a superior combatant officer, the medical officer attending only for the purpose of seeing that the soldier receives no unnecessary injury.

Fourthly (but this is of minor importance). It is desirable that the uniform of medical officers be made less objectionable. I would suggest that the unsightly black belts of the surgeons and assistant-surgeons be embroidered in the same manner as are those of inspector-generals; the different ranks are otherwise sufficiently distinguished; and we find in other branches of the army, officers of all ranks wearing belts similarly em. broidered.

Now, Sir, I write advisedly, and I feel sure that were these things granted we should not find any disadvantages in the Army Medical Service sufficiently great to deter the very best men of the profession from entering. At present, no doubt, it is not a service in which any gentleman can serve without enduring daily many little petty annoyances and insults which, collectively, embitter life.

I am, Sir, your obedient servant,

August 19th, 1864. A SURGEON.

\section{A JAY IN BORROWED PLUMES.}

\section{To the Editor of The LaNCRT.}

SrR, - The following is the title \&c. of a low, advertising pamphlet, which, I regret to say, appears in the columns of The Times abont every other day :-

$$
\text { " Price 1s., post free } 12 \text { stamps, }
$$

"Dypsomania (Thirst Madness); or, the Philosophy, Pre. vention, Moral, Medical, and Hygienic Cure of Intemperance. By A. Hall, M.D. London: Judge and Co., 50, Carlton-road, Kentish-town."

As I am the only A. Hall, M.D., in the Medical Register, or in the "Medical Directory" for the United Kingdom, the impression may arise that I am the author of the publication. Will you, therefore, do me the favour of inserting these few lines in your widely circulated journal disclaiming all know. ledge of or connexion with the parties who have had the audacity of using my name and titie in association with any thing so degrading?

It is a remarkable fact, that $I$ am the only medical man in the United Kingdom-whether physician, doctor of medicine, or surgeon-whose Christian name begins with "A."; and, farther, that there is no one of my name even in the medical profession of Scotland, and only one in Ireland. There can be no doubt, therefore, that my name and title have been falsely assumed by the writer of the quack pamphlet; and I shall esteem it a great favour if you will advise me how to act in the matter: whether I should try by an interdict to get the publication suppressed, or that I should lay my grievance before the General Medical Council and ask their aid in my dilemma. I am, Sir, your obedient servant,

\section{Old Stegne, Brighton, August, 1864.}

$$
\text { ALFRED HALL, M.D. Edin., M.R. C.P. Lond. }
$$

* * We should certainly advise Dr. Hall to appeal to the Medical Council, although we can give but feeble hopes of his obtaining redress unless he can identify the real anthor of the pamphlet. The reputation of our correspondent, however, stands deservedly too high to be affected by such a circum. stance.-ED. L.

\section{THE INCUBATION OF SCARLATINA.}

\section{To the Editor of THE LANCET.}

SIR, - I send you the particulars of the following cases, which may help to throw some light on this question. Dr. Murchison's cases are principally valuable in so far as they fix the limits of the receipt of infection. Dr. Thomson's do not, but have their practical use in deciding when a patient may be removed from quarantine. It would seem, however, that when it is once granted that the poisen may stick to clothes, \&c., it is almost hopeless to expect to fix the extreme limit of its power to infect, since we cannot make quite sure of their thorongh purification.

H. C- arrived at home on the 5th of April last. There was no case of scarlatina within several miles. She had travelled nearly forty miles, but might have caught the infection in a railway.carriage. She felt slightly ailing on the $27 \mathrm{th}$, and there was some rash on the 28 th.

Her father went to see his son (who died of the fever) on the 14th, and was very ill on the 21st of January, 1849. He had travelled the same distance from the country, where he had been in contact with no case of the disease.

Her mother went to see a schoolfellow, felt, as she says, that she had swallowed the poison, and was so ill within twelve hours as to be almost speecinless.

E. T-, aged twenty-one, sickened of scarlatina on the 29th of January last. Her brother, who was the last of his family to take it, was able to be out of doors in the last week of October, 1863. There was no communication between her father's and brother's house, until a niece came to live at the former and slept with her aunt on the 2 nd of January. She left again on the $7 \mathrm{th}$, which fixes the date of infection from the twenty-second to the twenty-seventh day. This case is also interesting as showing the length of time the poison lurks in fomites. E. T. had not been from home, and, to my assured knowledge, there had been no case of scarlatina within at least three or four miles of ber dwelling.

I am, Sir, your obedient servant,

Crimond, Peterhead, Aug. 1864. William BRUCe, M.D.

\section{To the Editor of THE LANCET.}

SIR, - With reference to the latent period of scarlet fever, which Dr. Marchison appears to consider does not extend beyond six days, I beg to send you notes of two cases recorded in my medical case-book, which appear to me to be of interest to the profession.

Mr. R. B. A-, naval cadet H.M.S. North Star, was added to the sick-list on the 23rd of February (A.M.), 1842, complaining of sore-throat and of having felt unwell for two days. At the P.M. visit his throat felt worse, and his skin very itching; considerable redness of velum and tonsils, and a scarlatina rash on chest, which soon became also visible on the extremities, and was followed by desquamation in a few days. H.M.S. North Star left England on the 18th of December, 1841, and arrived at Madeira on the $26 \mathrm{th}$, where she remained until the lst of Jannary, i842 ; and on the 24th of February we anchored in Table Bay, Cape of Good Hope, without having held communication with any shore or vessel between the two latter places. When he was taken ill he informed me that daring our stay at Madeira he visited an English clergyman, in whose family there had been scarlatina a very short time previously. The clothes which he wore at Madeira were, most probably, worn on each succeeding Sunday during the voyage.

Mr. J. M. B-, midshipman H.M.S. Shannon, was entered on sick-list on the 2nd of May, 1857, for a wound of foot; and on the 7 th P. M. he was suddenly seized with sore-throat, vomiting and febrile symptoms; tonsils and velum inflamed. On the 9th A.M. swallowing was very painful ; tonsils, velum, \&c., very red; tongue thickly coated with numerous prominent papillæ; pulse 140 ; greatly prostrated; skin hot and dry; a scarlatina rash on chest and extremities. Discharged to the Royal Naval Hospital, Simon's Town, Cape of Good Hope, for further treatment. He there became delirious, but subsequently recovered. H.M.S. Shannon left England on the 25th of February, 1857, and arrived in Simon's Bay, Cape of Good Hope, on the 7 th of May, without even having seen any land or having boarded any vessel. Mr. B. informed me that some children near his father's residence, at Southsea, had scarlatina when we were at Portsmouth in February. I am, Sir, your obedient servant,

August, 1364 W. M. SAUNDERS, M.D., Staff-surgeon R.N.

\section{VASO-MOTOR THERAPEUTICS. To the Editor of THE Lancet.}

Sir,-In The Laxcet of Jnne 4th last I read with great interest a paper by Dr. John Chapman on what he terms Vasomotor Therapeutics. A short time since I endeavoured to apply his theory in a severe case of dysmenorrhagia of long 